tissue and still remain asymptomatic. One should suspect intracranial penetration in all penetrating orbital injury and evaluate the extent of damage with computed tomography and MRI if a wooden foreign body is suspected. Plain radiographs have limited value.
1 Mutlukan E, Fleck BW, Cullen JF, et al. Case of penetrating orbitocranial injury caused by wood. $\mathrm{Br} \mathrm{J}$ Ophthalmol 1991;75:374-6.

2 Oguz M, Aksungur EH, Atilla E, et al. Orbitocranial penetration of a pencil: extraction under CT control. Eur J penetration of a pencil:

3 Specht CS, Varga JH, Jalali MM, et al. Orbitocranial wooden foreign body diagnosed by magnetic resonance imaging. Dry wood can be isodense with air and orbital fat by computed tomography. Surv Ophthalmol 1992;36:341-4.

\title{
Neurogenic pulmonary oedema
}

\author{
Gary W Kerr
}

\begin{abstract}
Neurogenic pulmonary oedema is a relatively rare but significant complication of head injury. A case is described and the presentation, pathophysiology, and management are discussed.

( Accid Emerg Med 1998;15:275-277)
\end{abstract}

Keywords: neurogenic pulmonary oedema; head injury

\section{Case report}

A 21 year old man was brought by ambulance to the accident and emergency department after having been assaulted while out drinking and left lying unconscious. He had a Glasgow coma score of 8 and soft tissue evidence of head trauma with abrasions and swelling over the right parietal area. The airway was clear with no blood, secretions, or vomit and he was tolerating a Guedal airway. There was no evidence of trauma anywhere else on his body. Examination was otherwise unremarkable apart from the presence of bilateral crackles on auscultation of the lung fields. Despite high flow oxygen via a reservoir mask his saturation on pulse oximetry was $91 \%$.

The patient was intubated and ventilated but the saturation remained at $91 \%$ with an arterial oxygen tension of $8.5 \mathrm{kPa}$ and a carbon dioxide tension of $5.1 \mathrm{kPa}$. A portable chest $x$ ray was performed and this showed perihilar alveolar shadowing later reported as being consistent with pulmonary oedema. There was prolonged difficulty in oxygenating the patient, requiring a large tidal volume, positive end expiratory pressure, and frequent suction of frothy bloodstained fluid via the endotracheal tube. The oxygen saturation gradually improved and the patient was taken to the computer tomography room.

A computed tomogram was performed which showed multiple high attenuation areas in the grey white matter interface of both frontal lobes with marked soft tissue swelling and a little blood in the subarachnoid space. These appearances were thought to be consistent with diffuse axonal injury.

After the tomogram there was a sudden deterioration with hypoxia, hypotension, and an increased central venous pressure. The patient responded to vigorous ventilation and adrenaline aliquots to maintain the blood pressure. As the chest $x$ ray was thought possibly to show a globular heart shadow, an echocardiogram was performed. This revealed poor left ventricular function with marked anteroapical hypokinesia but no pericardial effusion.

$\mathrm{He}$ was transferred to the intensive care unit where he was treated with frusemide, dobutamine, adrenaline, and ventilation with positive end expiratory pressure. During the next 24 hours he had a further hypoxic episode with increased pulmonary artery wedge pressure and oedema. This responded to diuretics, dobutamine, and glyceryl trinitrate. Subsequently he was cardiovascularly stable with no further episodes of pulmonary oedema and he was extubated before being transferred from the intensive care unit eight days after admission. His neurological recovery was minimal and he was transferred to a long term rehabilitation unit.

\section{Discussion}

When a patient with a head injury presents with the clinical features of pulmonary oedema there may not be an obvious explanation such as aspiration or excessive fluid administration. Neurogenic pulmonary oedema is a relatively uncommon complication of acute cerebral insults of various types and has been previously recognised as being the sole pathological mechanism in certain cases. ${ }^{1}$ Most initial reports associated neurogenic pulmonary oedema as being precipitated by head injuries, ${ }^{2-4}$ a finding emphasised by a report of 56 casualties from the Vietnam war with major head trauma that describes evidence of pulmonary oedema in 17 patients. ${ }^{5}$ Isolated head injury is still the commonest association, but a variety of other precipitants have been reported including epilepsy, ${ }^{6-9}$ subarachnoid haemorrhage, ${ }^{10-12}$ cerebral emboli, ${ }^{13}$ and induction of anaesthesia. ${ }^{14}$

The incidence is hard to determine as less severe cases may be unrecognised or attributed to aspiration. Graf and Rossi identified only two cases from a review of 2100 head injuries, ${ }^{15}$ but a more recent report gives an incidence of $0.62 \%$ in isolated head injuries, ${ }^{16}$ and one intensive care unit dealt with 20 cases over a 45 month period. ${ }^{17}$ 
Although many of the case reports involve children or young adults, ${ }^{31141819}$ a review of 20 patients ${ }^{17}$ had an age range of 11 to 71 and demonstrated no clear relation to age. There is also no literature documenting any other association such as preceding alcohol or drug ingestion.

Typically the patient unexpectedly develops pulmonary oedema after a head injury or subarachnoid haemorrhage. In addition to the hypoxia and frothy sputum, there may be peripheral vasoconstriction with pallor, sweating and a rapid, weak pulse. ${ }^{18} 20$

Despite experimental work with animals ${ }^{2122}$ the pathophysiology is not fully understood but probably both hydrostatic pressure and altered capillary permeability play a part in the pathogenesis. An acute cerebral insult with raised intracranial pressure is followed by massive release of catecholamines by the sympathetic system probably caused by a disturbance of hypothalamic function. This leads to a large and rapid increase in systemic and pulmonary blood pressures while the cardiac output falls due to the massively increased peripheral resistance. As a result of this there is a redistribution of blood volume from the systemic to the pulmonary circulation and this leads to pulmonary venous and left atrial engorgement. It has been suggested that the subsequent rise in pulmonary capillary pressures results not only in hydrostatic oedema but also damages the pulmonary endothelium so that a permeability effect persists after resolution of the pressure changes. ${ }^{23}{ }^{24}$ Other experiments have described how increased pulmonary permeability and oedema can follow a cranial injury without the pulmonary vascular pressures being raised. ${ }^{22}$ Alternative mechanisms such as direct $\alpha$ adrenergic effects on endothelial cells or release of histamine due to sympathetic stimulation have also been suggested, ${ }^{25}$ although experimental work has discounted the possibility of large doses of catecholamines directly increasing microvascular permeability. ${ }^{26}$ However the protective effect of cervical transection ${ }^{57}$ and results demonstrating that adrenergic blocking agents inhibit the development of neurogenic pulmonary oedema ${ }^{28}$ appear to confirm the key role of the sympathetic outflow in the pathogenesis.

As the pathophysiology is not fully understood the optimal treatment of neurogenic pulmonary oedema is not yet established. Generally, treatment is aimed at reduction of intracranial pressure, diuresis, and reversing the peripheral effects of the sympathetic stimulation. ${ }^{19}$ Controlled hyperventilation with intermittent positive pressure ventilation and, if necessary, surgical decompression, are used to reduce intracranial pressure. Diuretics, usually frusemide or mannitol, are used to reduce blood volume and intracranial pressure. The depression of myocardial function generally associated with neurogenic pulmonary oedema has been shown to be reversed by dobutamine ${ }^{17}$ and the combination of a positive inotrope and a vasodilator is an established method of improving cardiac output. ${ }^{3}$ The mortality of head injury patients with associated neurogenic pulmonary oedema may exceed $90 \% .^{29}$ It is also commonly found in epileptics who die suddenly after an otherwise unremarkable fit. ${ }^{67}$

Neurogenic pulmonary oedema is an uncommon complication of cerebral trauma but the diagnosis should be considered in appropriate cases. The mortality is high and early aggressive treatment is required to improve chances of recovery. Confusion with presentations such as aspiration may delay recognition and prevent optimal management thus compounding the effects of an already serious cerebral insult.

1 Phillips JF, Neiman HL, Reeder MM. Non-cardiac causes of pulmonary oedema. JAMA 1975;234:531-2.

2 Cohen HH, Gambill AF, Eggers GWN. Acute pulmonary oedema following head injury. Anaesthesia and Analgesia. Current Researches 1977;56:136-9.

3 Ager JM. Head injury in the adolescent: medical complications in the early management. Med J Aust 1966;ii:1182-3.

4 Bean JW, Beckman DL. Centrogenic pulmonary patholog in mechanical head injury. J Appl Physiol 1969;27:807-12.

5 Simmons RL, Martin AM, Heisterkamp CA, et al. Respiratory insufficiency in combat casualties. Pulmonary oedema tory insufficiency in combat casualties. Pulmonary
following head injury. Ann Surg 1969; 170:39-44.

6 Fredberg U, Botker HE, Romer FK. Acute neurogenic pulmonary oedema following generalised tonic clonic seizure. Eur Heart J 1988;9:933-6.

7 Terrence CF, Rao GR, Perper JA. Neurogenic pulmonary oedema in unexpected, unexplained death of epileptic patients. Ann Neurol 1981;9:458-64

8 Buisseret P. Acute pulmonary oedema following grand mal epilepsy and as a complication of electric shock therapy. British Journal of Diseases of the Chest 1982;76:194-8.

9 Darnell JC, Jay SJ. Recurrent postictal pulmonary oedema: a case report and review of the literature. Epilepsia 1982;23:71-83.

10 Carlson RW, Shaeffer RC, Michaels SG, et al. Pulmonary oedema following intracranial haemorrhage. Chest 1979 75:731-34.

11 Lear GH. Neurogenic pulmonary oedema. Acta Paediatr Scand 1990;79:1131-3.

12 Fisher A, Aboul-Nasr HT. Delayed non-fatal pulmonary oedema following subarachnoid haemorrhage. J Neurosurg

13 Reines HD, Dill L, Saad S, et al. Neurogenic pulmonary oedema and missile emboli. J Trauma 1980;20:698-701.

14 Braude N, Ludgrove T. Neurogenic pulmonary oedema precipitated by induction of anaesthesia. $\mathrm{Br} \mathrm{J}$ Anaesth 1989;62:101-3.

15 Graf CJ, Rossi NP. Pulmonary oedema and the central nervous system: a clinico-pathological study. Surg Neuro 1975;3:319-25.

16 Singbartl G. Permeability pulmonary oedema following isolated head and brain injury. Anaesthetist 1983;32:417-26.

17 Deehan SC, Grant IS. Haemodynamic changes in neurogenic pulmonary oedema: effect of dobutamine. Intensive Care Medicine 1996;22:672-6.

18 Casey WF. Neurogenic pulmonary oedema. Anaesthesia $1983 ; 38: 985-8$

19 Wauchob TD, Brooks RJ, Harrison KM. Neurogenic pulmonary oedema. Anaesthesia 1984;39:529-34.

20 Marshall M. Neuroanaesthesia. London: Edward Arnold, 1979.

21 Garcia-Uria J, Hoff JT, Miranda BA, et al. Experimental pulmonary oedema. J Neurosurg 1981;54:632-36.

22 Millen JE, Glauser FL. Low levels of concussive brain trauma and pulmonary oedema. J Appl Physiol 1983;54: 666-70.

23 Theodore J, Robin ED. Pathogenesis of neurogenic pulmo-

24 West JB, Mathieu-Costello O. Stress failure of pulmonary capillaries: role in lung and heart disease. Lancet 1992;340:762-7.

25 Colice GL, Matthay MA, Bass E, et al. Neurogenic pulmonary oedema. Am Rev Respir Dis 1984;130:941-48.

26 Shibamoto T, Wang HG, Tanaka S, et al. No effects of large doses of catecholamines on vascular permeability in isolated blood-perfused dog lungs. Acta Physiol Scand 1995; 155:127-35.

27 Nilsson B, Ponten U, Voight G. Experimental head injury in the rat. J Neurosurg 1977;47:241-51.

28 Van der Zee H, Malik AB, Lee BC, et al. Lung fluid and protein exchange during intracranial hypertension and the role of sym $273-80$.

29 Ducker TB. Increased intracranial pressure and pulmonary oedema. J Neurosurg 1968;28:112-7. 